\title{
Dimensioning IRGA gas sampling systems: laboratory and field experiments
}

\author{
Marc Aubinet ${ }^{1}$, Lilian Joly ${ }^{2}$, Denis Loustau ${ }^{3}$, Anne De Ligne ${ }^{1}$, Henri Chopin ${ }^{1}$, Julien Cousin ${ }^{2}$, Nicolas Chauvin ${ }^{2}$, \\ Thomas Decarpenterie ${ }^{2}$, and Patrick Gross ${ }^{4}$ \\ ${ }^{1}$ University of Liège, Gembloux Agro-Bio Tech, TERRA, Ecosystems - Atmosphere Exchanges, \\ Liège, Belgium \\ ${ }^{2}$ University of Reims, Groupe de Spectrométrie Moléculaire et Atmosphérique, Reims, France \\ ${ }^{3}$ INRA, UMR ISPA, 33140 Villenave d'Ornon, France \\ ${ }^{4}$ INRA, UMR EEF, 54280 Champenoux, France \\ Correspondence to: Marc Aubinet (marc.aubinet@ulg.ac.be)
}

Received: 6 September 2015 - Published in Atmos. Meas. Tech. Discuss.: 20 October 2015

Revised: 23 December 2015 - Accepted: 27 February 2016 - Published: 31 March 2016

\begin{abstract}
Both laboratory and field experiments were carried out in order to define suitable configuration ranges for the gas sampling systems (GSSs) of infrared gas analyzers (IRGAs) used in eddy covariance measurements.

In the laboratory, an original dynamic calibration bench was developed in order to test the frequency attenuation and pressure drop generated by filters. In the field, three IRGAs of the same type equipped with different filters or different rain caps were installed and run and the real frequency response of the complete setup was tested.

The main results are as follows.

- Filters may have a strong impact on the pressure drop in the GSS and this impact increases with flow rate.

- Conversely, no impact of the tested filters on cut-off frequency was found, GSSs with and without filters presenting similar cut-off frequencies.

- The main limiting factor of cut-off frequency in the field was found to be the rain cap design. In addition, the impact of this design on pressure drop was also found to be noteworthy.
\end{abstract}

\section{Introduction}

The use of the eddy covariance technique to study gas exchange between ecosystems and the atmosphere has greatly developed in the last decades (Baldocchi, 2014) and is not limited to $\mathrm{CO}_{2}$ and $\mathrm{H}_{2} \mathrm{O}$ exchanges, but expands to more and more trace gases like methane, $\mathrm{N}_{2} \mathrm{O}$ or volatile organic compounds. Several networks using eddy covariance with the aim of characterizing ecosystem functioning across a spectrum of pedoclimatic conditions have been implemented (Valentini et al., 2000; Baldocchi et al., 2001; Ciais et al., 2010). However, to work correctly, eddy covariance systems require careful attention to system configuration. This concerns especially the infrared gas analyzer (IRGA) and sonic choice, their positioning and, as far as closed or semi-closed IRGAs are concerned, the gas sampling system (GSS), which carries air from the sampling point to the infrared gas analyzer (IRGA). The GSS has to meet several constraints, among which are the protection of the IRGA against dust and rain, the minimization of high-frequency attenuation of concentration fluctuations and the maintenance of pressure drop in the measurement cell in an acceptable range. Rain cap, filter, tube and pump are key elements of this system and need proper dimensioning. The experiments described in this paper were prompted by discussions held within the framework of the ICOS project with the aim of optimizing GSS dimensions. Following these discussions, several teams worked on these topics (Metzger et al., 2016). In the present research, 
both laboratory and field experiments were carried out in order to determine the impact of filters and rain caps on pressure drop in the IRGA chamber and on the high-frequency concentration attenuation.

In the laboratory, a dynamic calibration bench was developed that generated different flow rates and concentration fluctuation frequencies in order to test the frequency response of some filters and to measure the pressure drop they generated. In the field, three identical IRGAs equipped with different GSSs were installed and run at a grassland site and the real frequency response of the complete setup was tested. This paper summarizes these experiments and provides recommendations for GSS dimensioning.

\section{Theory}

In addition to the necessity of keeping the cell clean, the main constraints on the GSS are the needs to maintain the pressure drop inside the chamber above a critical threshold (depending on IRGA type) and the concentration fluctuation frequencies as high as possible.

The pressure drop through the GSS depends on air flow rate, on tube length and diameter but also on turns, diameter changes or porous media crossings that are frequent in GSSs, due to the presence of filters or rain caps. The part of the pressure drop due to the linear tube can be described by the Darcy-Weisbach equation (e.g., Sayers, 1992; Massel, 1999):

$\Delta p=\frac{8 \rho Q^{2} \lambda L_{\mathrm{t}}}{\pi^{2} d_{\mathrm{t}}^{5}}$,

where $\rho$ is the air density, $Q$ is the flow rate in the tube, $L_{\mathrm{t}}$ and $d_{\mathrm{t}}$ are the tube length and diameter and $\lambda$ is the friction factor, for which a conservative value of 0.047 may be chosen (see, e.g., Sayers, 1992). This equation is useful to predict the pressure drop through the GSS in the absence of filters or rain caps.

The frequency responses of eddy covariance systems have been studied by several authors like Moore (1986), Leuning and King (1992), Leuning and Judd (1996) or Massman and Ibrom (2008). These authors identified sensor response, sensor-line averaging and concentration fluctuation attenuation through the tube as most probable causes of highfrequency losses in closed and enclosed systems. They proposed a quantification of the transfer function for each process. We will not recall them all here (to obtain a synthesis, see for example Foken et al., 2012) but we simply focus on those we supposed to be the most determinant for the present setup. Indeed, by quantifying the different transfer functions characterizing the IRGA and the GSS used in the present analyses (see Sect. 3.1), it appeared that the tube attenuation and the sensor response were probably not limiting and that the most limiting process, in the absence of filters or rain caps, was the line sensor averaging. An expression of the associated transfer function, derived from Moore (1986) and adapted to a measurement chamber of length $L_{\mathrm{c}}$ and diameter $d_{\mathrm{c}}$, is

$\operatorname{TF}(f)=\left|\frac{\sin \left(\frac{\pi^{2} d_{\mathrm{c}}^{2} L_{\mathrm{c}} f}{4 Q}\right)}{\frac{\pi^{2} d_{\mathrm{c}}^{2} L_{\mathrm{c}} f}{4 Q}}\right|$,

where $Q$ is the flow rate in the measurement chamber and $f$ is the frequency. Associated cut-off frequency may then be computed as the frequency where this function equals $\frac{1}{\sqrt{2}}$. Again these estimates are useful to estimate the cut-off frequency of a system without filters or rain caps.

\section{Material and methods}

\subsection{Laboratory experiment}

\subsubsection{Gas sampling system and pressure drop measurements}

A dynamic calibration bench was developed at the Groupe de Spectrométrie Moléculaire et Atmosphérique (GSMA, University of Reims) to investigate the pressure drop and the concentration fluctuation attenuation caused by different filters without a rain cap experimentally. For these experiments, the flow rate in the GSS was generated by a pump (KNF, N 026.1.2 AN.18, Village Neuf, France). The GSS was constituted, from upstream to downstream, by a filter, a $1 \mathrm{~m}$ length, $5.3 \mathrm{~mm}$ diameter tube, the IRGA (LI-7200, LICOR, Lincoln, Nebraska), a mass flow controller (Vögtlin MC-50SLPM-D-I/5M-5IN Gaz, Aesch, Switzerland) driven by a computer, a buffer in order to dampen pump fluctuations and, finally, the pump. Concentrations measured by the IRGA were sampled at $20 \mathrm{~Hz}$ and the data were collected and stored on a computer. Experiments were repeated four times, once without a filter and three times with different filters: ACRO $501 \mu \mathrm{m}$ (PALL, Port Washington, NY, USA), Swagelok FW $2 \mu \mathrm{m}$ (Swagelok, Solon, OH, USA) and PALL open-face filter holder with a $2 \mu \mathrm{m}$ membrane (PALL, Port Washington, NY, USA).

In each experiment, one filter was installed at the system inlet and the mass flow was varied step by step from 1 to $28 \mathrm{~L} \mathrm{~min}^{-1}$. Chamber pressure measured by the analyzer was collected through the IRGA RS232 output and stored on the computer.

\subsubsection{GSS frequency response}

Concentration fluctuations at the GSS inlet were generated by diluting ambient air (with ambient $\mathrm{CO}_{2}$ concentration) with dry, $\mathrm{CO}_{2}$-free air (Alphagaz 1 air, Air liquide, France). The GSS inlet was placed in a nozzle, fed by ambient air 


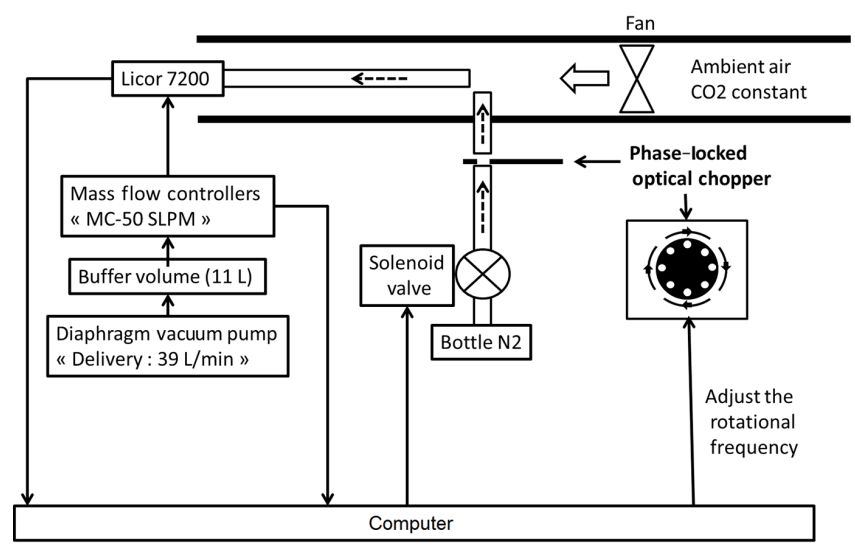

Figure 1. Calibration bench for cut-off frequency determination.

by a fan and into which $\mathrm{CO}_{2}$-free air was injected intermittently through a chopper (Fig. 1). The intermittent mixing of ambient and $\mathrm{CO}_{2}$-free air provoked $\mathrm{CO}_{2}$ concentration fluctuations. The frequency of the fluctuations was adjusted by modulating the chopper rotational frequency. One measurement cycle lasted for $150 \mathrm{~s}$ (Fig. 2a) and consisted of 20 successive phases with an alternation of $\mathrm{CO}_{2}$-free air injection or no injection. The injection modulation frequency was fixed to $1 \mathrm{~Hz}$ during the first injection phase and increased by $1 \mathrm{~Hz}$ between each successive injection phase (Fig. 2b); therefore, the investigated frequency range was 1 to $20 \mathrm{~Hz}$ with a $1 \mathrm{~Hz}$ resolution. For each filter, the cycle was repeated five times with different GSS flow rates, between 5 and $30 \mathrm{~L} \mathrm{~min}^{-1}$.

The independence of $\mathrm{CO}_{2}$-free air injection flow rate of chopper modulation frequency was checked during a previous validation phase; therefore, the amplitude of concentration fluctuations could be considered as independent of injection modulation frequency.

An example of concentration measurement by the IRGA during one measurement cycle is illustrated in Fig. 2. As the concentration fluctuation amplitude in the nozzle was constant, the amplitude decrease with injection modulation frequency can only result from frequency attenuation by the GSS and the IRGA. The system cut-off frequency was then computed as the frequency at which the concentration fluctuation amplitude was divided by $\sqrt{ } 2$ (Fig. 2a).

\subsection{Field experiment}

\subsubsection{Site and setup description}

Site measurements were performed at the Dorinne (DTO) and Vielsalm (VTO) terrestrial observatories. The first is grazed permanent grassland and the second is mixed forest. As the site choice is not critical for the experiments, which concern mainly the IRGA setup, site details are not given here. They can be found in Jérôme et al. (2014) for DTO and in Aubinet et al. (2001) for VTO. Both sites are equipped with an eddy covariance system and a microme-

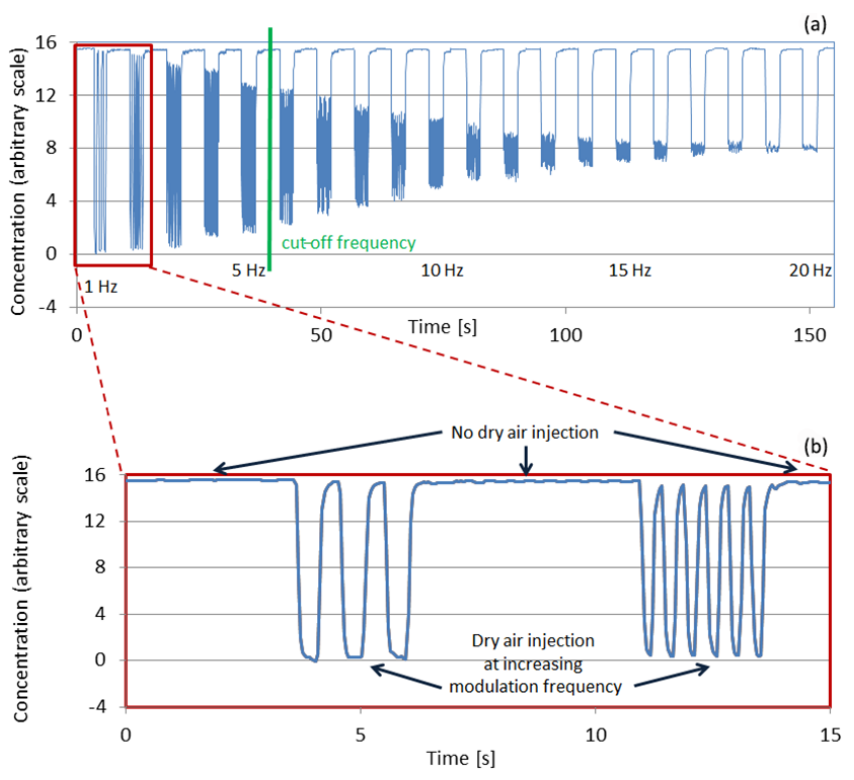

Figure 2. Recording of concentration measurements by the IRGA during one measurement cycle. (a) Representation of the whole cycle. The frequencies given in the figure are the concentration modulation frequencies. (b) Focus on the first $15 \mathrm{~s}$. For details, see text.

teorological station. From July to October 2013, we tested the impact of filters on pressure drop and cut-off frequency. In addition to the system in place, one sonic anemometer (Gill HS 50, Gill, Lymington, UK) and three additional IRGAs (LI-COR-7200, LI-COR, Lincoln, NE) were installed at DTO. They were placed in order to minimize the distance between the IRGA sampling point and the sonic path volume. In practice, the horizontal and vertical separation distances between the sampling point and the sonic path volume were lower than 15 and $24 \mathrm{~cm}$, respectively. In addition, the sonic anemometer boom and IRGA tubes were all oriented perpendicularly to the main wind direction. All three IRGAs were equipped with a rain cap (intake screen LI-COR 9972-043) and a tube with the same dimension $(1 \mathrm{~m}$ length, $5.3 \mathrm{~mm}$ diameter). Different flow rates, filters and rain cap configurations were tested. They are summarized in Table 1. In October 2013 we tested the impact of rain cap design: one IRGA was maintained at the sites, fed by a $15 \mathrm{~L} \mathrm{~min}^{-1}$ flow rate and equipped with the same tube, a Swagelok FW $2 \mu \mathrm{m}$ filter and rain caps of different design. Specifically, in addition to the original LI-COR rain cap (volume $27 \mathrm{~mL}$ ), two homemade rain caps were tested as well as a simple stuffing gland. The first homemade rain cap (HM1, total volume $5 \mathrm{~mL}$ ) had a $25 \mathrm{~mm}$ entrance diameter, a $22 \mathrm{~mm}$ depth and a conical profile. The aspiration tube was in the axis of the cap. The second one (HM2, total volume $7.4 \mathrm{~mL}$ ) had a $21 \mathrm{~mm}$ entrance diameter, a $21 \mathrm{~mm}$ depth and a cylindrical profile. The aspiration tube was placed on the lateral surface. The stuffing gland had an entrance volume of $0.9 \mathrm{~mL}$. The new LI-COR intake screen 9972-072 (LI-COR, Lincoln, NE, total volume 
$3.2 \mathrm{~mL}$ ) was tested as soon as it was provided, in April 2014. The system was identical to the preceding one but was installed at VTO.

\subsubsection{Data treatment}

Set up transfer functions of field data were computed as the ratio of $\mathrm{CO}_{2}$ and temperature power spectra. Power spectra were computed on six successive half hours, free of spikes and of step changes (Vickers and Mahrt, 1997), satisfying stationarity criteria (Foken and Wichura, 1996) and for which sensible heat was larger than $25 \mathrm{~W} \mathrm{~m}^{-2}$ and $\mathrm{CO}_{2}$ fluxes were larger than $2 \mu \mathrm{mol} \mathrm{m} \mathrm{m}^{-2} \mathrm{~s}^{-1}$. Computation was made using the EDDYFLUX software (Kolle and Rebmann, 2007). The ratio of mean spectra was computed, giving an experimental transfer function. As power spectra were considered here, the cut-off frequency is the frequency for which the transfer function is divided by two. Consequently cut-off frequencies $\left(f_{0}\right)$ were computed as a result of Gaussian relation fitting on the experimental transfer functions $(\delta)$ :

$\delta=\exp \left\{-\ln 2 \frac{f^{2}}{f_{\mathrm{co}}^{2}}\right\}$,

where $f$ is the frequency.

\section{Results}

\subsection{Laboratory measurements}

\subsubsection{Pressure drop}

The response to flow rate of pressure drop along the tube and the filters (without rain caps) was measured in the laboratory (Fig. 3). In addition, the predicted pressure drop along the tube (Eq. 1) is presented by the continuous line. In each case, the pressure drop nonlinearly increased with mass flow. In the absence of a filter, the increase is described by the theoretical curve with a $0.3 \mathrm{kPa}$ accuracy. In addition, the other curves show that the presence of a filter always enhances the pressure drop and that the filter impact increases with flow rate. At $15 \mathrm{~L} \mathrm{~min}^{-1}$, it is more than $9 \mathrm{kPa}$ for the ACRO 50 $1 \mu \mathrm{m}$, about $1.1 \mathrm{kPa}$ for the PALL $2 \mu \mathrm{m}$ and $0.55 \mathrm{kPa}$ for the Swagelok FW 2. This latter result coincides well with the findings by Metzger et al. (2016) (Their Fig. 3a). This shows that filters contribute significantly to the pressure drop in the GSS, and are in some cases the main cause of this drop. It also appears that the largest pressure drop was observed for the filter with lower pore size and smaller exchange surface.

\subsubsection{Cut-off frequency}

The response to flow rate of the cut-off frequency due to the sensor line averaging, the tube and the filters (without rain cap) was measured in the laboratory with the setup described in Sect. 3.1.2 (Fig. 2). The results are given in Fig. 4.

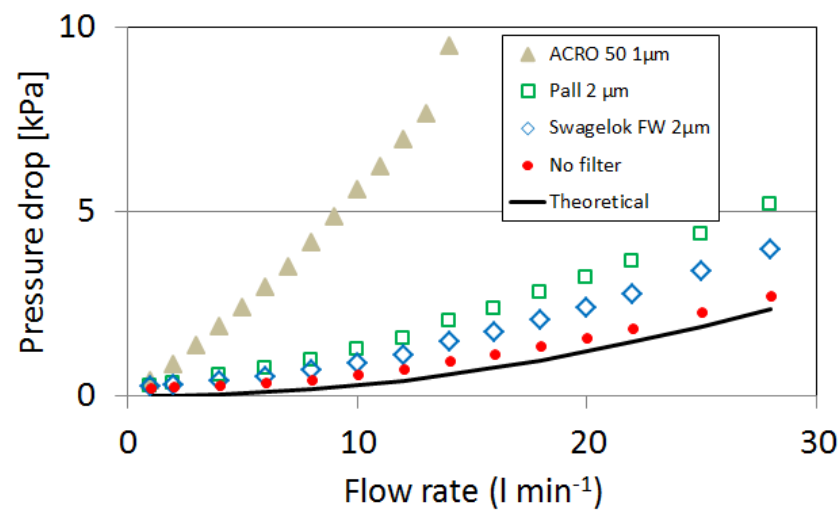

Figure 3. Pressure drop in the IRGA cell $(\mathrm{kPa})$ as a function of the flow rate $\left(\mathrm{L} \mathrm{min}^{-1}\right)$ for different filters: ACRO 50 (triangles), PALL $2 \mu \mathrm{m}$ (squares), Swagelok FW $2 \mu \mathrm{m}$ (diamonds) and without any filter (dots). The theoretical curve (Eq. 1) is given by the continuous line.

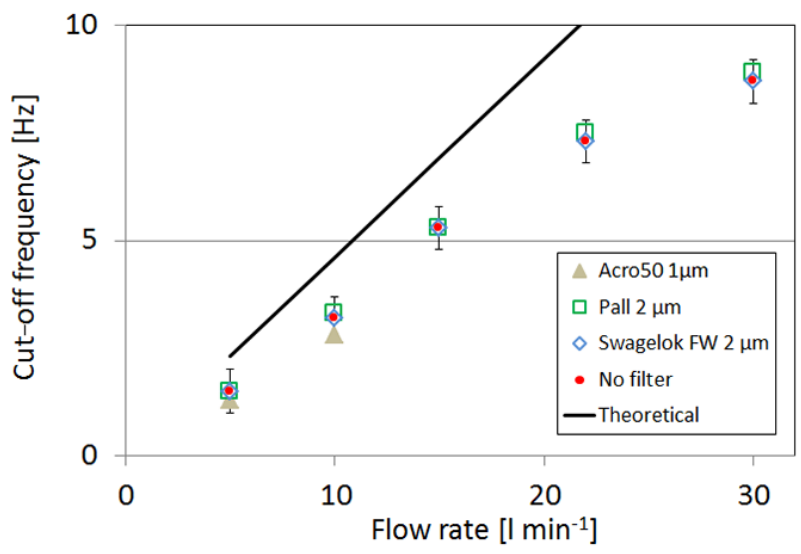

Figure 4. Cut-off frequencies $(\mathrm{Hz})$ as a function of the flow rate $\left(\mathrm{L} \mathrm{min}^{-1}\right.$ ) for LI-7200 with ACRO 50 (grey triangle), PALL $2 \mu \mathrm{m}$ (green squares), Swagelok FW $2 \mu \mathrm{m}$ (blue diamonds), and without any filter (red dots). The full line corresponds to the theoretical prediction given by Eq. (2).

Observed cut-off frequencies appear 30-40\% lower than those predicted by Eq. (2). In view of the mass flow and tube dimensions, the difference cannot be explained by tube attenuation. This suggests that another, unidentified process causes high cut filtering. Anyway, the most important point is that cut-off frequencies do not differ significantly between GSSs with and without filters and among GSSs with different filters. This clearly suggests that, contrary to earlier guesses (e.g., Aubinet et al., 2001), none of the tested filters had any effect on the system cut-off frequency.

\subsection{Field results}

Results from the first campaign are summarized in Table 1. They clearly differed from laboratory results as GSS cut-off frequencies observed in the field were much (almost a decade 
Table 1. Schedule of filter, flow rate and rain cap design used at the field site. Average cut-off frequencies measured on each system tested.

\begin{tabular}{lllllr}
\hline & Filter & Flow rate & Rain cap & Date & Cut-off frequency $(\mathrm{Hz})$ \\
\hline System 1: & ACRO 50 1 $\mu \mathrm{m}$ & 6 slpm & LI 9972-043 & 5 Jul-2 Sep & $0.75 \pm 0.08$ \\
System 2a & Swagelok 2 $\mu \mathrm{m}$ & 15 slpm & LI 9972-043 & 5 Jul-2 Sep & $1.36 \pm 0.12$ \\
System 2b & Swagelok 2 $\mu \mathrm{m}$ & 15 slpm & Stuffing gland & 2-26 Sep & $8.0 \pm 2.9$ \\
System 2c & Swagelok 2 $\mu \mathrm{m}$ & 20 slpm & Stuffing gland & 26 Sep-9 Oct & $7.87 \pm 0.76$ \\
System 3a & Savillex 2 $\mu \mathrm{m}$ & 15 slpm & LI 9972-043 & 5-31 Jul & $0.62 \pm 0.03$ \\
System 3b & PALL 2 $\mu \mathrm{m}$ & 15 slpm & LI 9972-043 & 31 Jul-26 Aug & $0.89 \pm 0.13$ \\
System 3c & PALL 3 $\mu \mathrm{m}$ & 15 slpm & LI 9972-043 & 26 Aug-2 Sep & $0.76 \pm 0.20$ \\
\hline
\end{tabular}

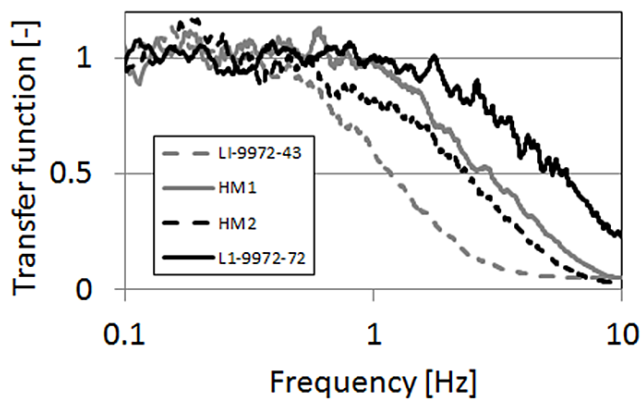

Figure 5. Transfer functions corresponding to different rain cap designs. Legend: dotted grey line: LI-9972-043; full grey line: HM1; dotted black line: HM2; full black line: LI-9972-072.

in some cases) lower than in the lab. As the main difference between designs tested in the lab and in the field was the introduction of the rain cap in the latter, we conclude that the main cause of cut-off frequency decrease should be due to the rain cap. This is confirmed by the experiments made with systems $2 b$ and $2 c$, where the rain cap was replaced by a simple stuffing gland. In these conditions, cut-off frequency reached much higher values that were more compatible with lab observations.

The second field campaign was thus held in order to test different rain cap designs and evaluate their frequency response. Some transfer functions obtained during the experiment are shown in Fig. 5. All these functions were obtained with identical GSS (i.e., same tube, filter, flow rate; see Sect. 3.2.1), differing only by the rain cap design. It is clear that this characteristic is critical as resulting cut-off frequencies varied from 1 to more than $5 \mathrm{~Hz}$ according to the rain cap design. In particular, cut-off frequency appeared strongly linked with the rain cap volume (Fig. 6). It was also observed that the pressure drop created by a rain cap could differ strongly from one design to another. Observed pressure drops along the GSS were $3.3,4.4,2.6$ and $2.0 \mathrm{kPa}$ at $15 \mathrm{~L} \mathrm{~min}^{-1}$ for the LI-9972-043, HM1, HM2 and LI-9972072 rain caps, respectively. However, these drops are due not only to the rain caps, but also to the filter. From Fig. 3, it is evident that the filter contribution to pressure drop is estimated to be around $1.6 \mathrm{kPa}$.

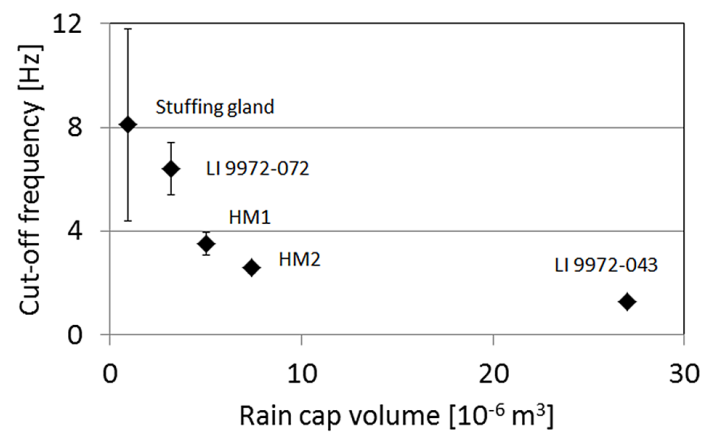

Figure 6. Relation between GSS cut-off frequency at a $15 \mathrm{~L} \mathrm{~min}^{-1}$ flow rate and rain cap volumes.

\section{Discussion and conclusions}

\subsection{Filter impact}

The laboratory experiment suggested that filters may have a strong impact on the pressure drop in the GSS and that this impact increases with flow rate. The relative impact of filters and tubes depends on their respective dimensions (pore size, exchange surface). In some cases this impact may be not critical, for instance, when closed-path analyzers are used with long tubes, when flow rates are limited or when constraints on chamber pressure are not too severe. In the specific case of the eddy covariance system recommended by the ICOS network, where the protocol recommended GSS cut-off frequency to be maximized and the IRGA chamber to be limited under pressure below $9 \mathrm{kPa}$ (Aubinet et al., 2016), this impact is critical and some filters (i.e., PALL ACRO $501 \mu \mathrm{m}$ ) would appear impracticable.

Quite unexpectedly, no impact of the tested filters on cutoff frequency was found. GSSs with and without filters presented similar cut-off frequencies. In addition, no difference in cut-off frequencies was found between filters characterized by different pore sizes ( 1 and $2 \mu \mathrm{m}$ ) or exchange surfaces. This study was, however, not exhaustive, not all types of filters having been tested. As it will be suggested below, the introduction of large volumes in the GSS may have a critical impact on cut-off frequency; therefore it is recommended that filters with large exchange volumes are avoided. 
We expect that filters with small pore size induce larger pressure drops. However, the use of a pore size that is too large would lead to insufficient chamber protection. This could provoke premature chamber dirtying or, more critically, destruction of the thermocouples that measure highfrequency air temperature fluctuations in the chamber of enclosed systems (LI-7200) and that are essential for density correction implementation. A compromise is thus needed, which is probably site-specific, depending on pollution level but also on pollen presence. At the field sites used in this study, filters with $5 \mu \mathrm{m}$ pore size have been found to be insufficient, provoking chamber dirtying after a few days while $1 \mu \mathrm{m}$ filters provoked a pressure drop that is too large. A pore size of $2 \mu \mathrm{m}$ appeared to be a good compromise, which could probably hold for many sites. This needs, however, to be checked individually at each site.

Practical considerations should also be taken into account when choosing a filter. Ease of use during maintenance is important; for example, changing membranes in filters with open-face holders is challenging, especially in difficult conditions like at the top of towers under windy conditions. In addition, the use of metallic filters could lead to problems at night as they are more prone to radiative cooling and may appear more frequently blocked by dew at sunset. They thus need heat protection and heating. Finally, filter duration is also an important criterion to consider in order to limit maintenance time and cost.

\subsection{Rain cap impact}

The comparison between laboratory and field experiments showed that, unexpectedly, the main limiting factor of cutoff frequency was the rain cap design. This design also impacted the pressure drop in the GSS significantly. The following points were raised after field tests.

- The rain cap volume should be as reduced as possible in order to avoid a cut-off frequency reduction; a compromise should be found between rain cap volume and its ability to protect the GSS from rain.

- Turns and flow restriction (even of short length) have been found to create pressure drops in the system and should be avoided.

As it was not the aim of this paper to investigate a substitution for the IRGA designers, no extensive research was made to optimize the rain cap design. A more complete investigation has been undertaken on this topic by Metzger et al. (2016) (see especially their Table 3 and Fig. 2, where transfer function and half power frequencies of separate or combined GSS elements are presented).

The new rain cap design proposed by LI-COR (LI-9972072) was tested successfully in the field and provided satisfying cut-off frequencies. Long-term field studies in rainy conditions are now needed to test their efficiency for GSS rain protection.
As soon as the filter and the rain cap have been optimized, spectral cut-off frequencies larger than $5 \mathrm{~Hz}$ can be reached. However, these values are larger than could be expected for fluxes measured by eddy covariance. Indeed, in this case, even if rain cap design and filter choice are optimized, other causes of high-frequency losses may appear, especially resulting from the spatial separation between the sonic path and the IRGA inlet. Cut-off frequencies larger than $3 \mathrm{~Hz}$ remain difficult to reach in these conditions. This value is sufficient anyway to limit the impact of high-frequency losses at most sites.

Acknowledgements. We thank Steve Sargent, Thomas Foken and two anonymous referees for their useful comments that really helped to improve the manuscript. Adrien Pâquet has welcomed our systems (and much more) in his meadow at DTO. This study was funded by the Service Public de Wallonie (Project ICOS Wallonia, convention 1217769).

Edited by: F. X. Meixner

\section{References}

Aubinet, M., Arriga, N., Aurela, M., Burba, G., Clement, G, De Ligne, A., Fratini, G., Gielen, B., Grace, J., Gross, P., Herbst, M., Haapanala, S., Ibrom, A., Joly, L., Kowalski, A., Lindroth, A., Loustau, D., Mammarella, I., Mauder, M., Merbold, L., Mölder, M., Metzger, S., Montagnani, L., Papale, D., Pavelka, M., Peichl, M., Serrano-Ortiz, P., Steinbrecher, R., Vesala, T., and Wohlfahrt, G.: Icos Ecosystem Variable Protocols: High Frequency Concentrations, in preparation, 2016.

Aubinet, M., Chermanne, B., Vandenhaute, M., Longdoz, B., Yernaux, M., and Laitat, E.: Long term carbon dioxide exchange above a mixed forest in the Belgian Ardennes, Agric. For. Meteorol., 108, 293-315, 2001.

Baldocchi, D., Falge, E., Gu, L., Olson, R., Hollinger, D., Running, S., Anthoni, P., Bernhofer, Ch., Davis, K., Evans, R., Fuentes, J., Goldstein, A., Katul, G., Law, B., Lee, X., Malhi, Y., Meyers, T., Munger, W., Oechel, W., Paw, U. K. T., Pilegaard, K., Schmid, H. P., Valentini, R., Verma, S., Vesala, T., Wilson, K., and Wofsy, S.: FLUXNET: A New Tool to Study the Temporal and Spatial Variability of Ecosystem-Scale Carbon Dioxide, Water Vapor, and Energy Flux Densities, B. Am. Meteorol. Soc., 82, 2415-2434, 2001.

Baldocchi, D.: Measuring fluxes of trace gases and energy between ecosystems and the atmosphere - the state and future of the eddy covariance method, Glob. Change Biol., 20, 3600-3609, 2014.

Ciais, P., Paris, J. D., and Rivier, L.: How to estimate greenhouse gases fluxes and associated uncertainties by using atmospheric measurements of the European ICOS network, Pollution Atmosphérique, Special issue: "Retour aux sources: La recherche et l'identification des sources de pollution", 59-62, 2010.

Foken, T. and Wichura, B.: Tools for quality assessment of surfacebased flux measurements, Agric. For. Meteorol., 78, 83-105, 1996.

Foken, T., Leuning, R., Oncley, S. R,. Mauder, M., and Aubinet, M.: Corrections and data quality control. in: Eddy Covariance: 
a Practical Guide to Measurement and Data Analysis, edited by: Aubinet, M., Vesala, T., and Papale, D., Springer Atmospheric Sciences, Springer, the Netherlands, doi:10.1007/978-94-0072351-1_4, 85-131, 2012.

Jérôme, E., Beckers, Y., Bodson, B., Heinesch, B., Moureaux, C., and Aubinet, M.: Impact of grazing on carbon dioxide exchanges in an intensively managed Belgian grassland, Agric. Ecosyst. Environ., 194, 7-16, 2014.

Kolle, O. and Rebmann, C.: Eddysoft - Documentation of a Software Package to Acquire and Process Eddy Covariance Data. 10, Technical Reports - Max-Planck-Institute for Biogeochemistry 10, Jena, Germany and Environment, 194, 7-16, 2007.

Leuning, R. and Judd, M. J.: The relative merits of open- and closed-path analyzers for measurements of eddy fluxes, Glob. Change Biol., 2, 241-254, 1996.

Leuning, R. and King, K. M.: Comparison of eddy covariance measurements of $\mathrm{CO}_{2}$ fluxes by open and closed-path $\mathrm{CO}_{2}$ analysers, Bound.-Lay. Meteorol., 59, 297-311, 1992.

Massel, S. R.: Fluid Mechanics for Marine Ecologists, Springer, Berlin, 566 pp., 1999.

Massman, W. J. and Ibrom, A.: Attenuation of concentration fluctuations of water vapor and other trace gases in turbulent tube flow, Atmos. Chem. Phys., 8, 6245-6259, doi:10.5194/acp-86245-2008, 2008.
Metzger, S., Burba, G., Burns, S. P., Blanken, P. D., Li, J., Luo, H., and Zulueta, R. C.: Optimization of an enclosed gas analyzer sampling system for measuring eddy covariance fluxes of $\mathrm{H}_{2} \mathrm{O}$ and $\mathrm{CO}_{2}$, Atmos. Meas. Tech., 9, 1341-1359, doi:10.5194/amt9-1341-2016, 2016.

Moore, C. J.: Frequency response corrections for eddy correlation systems, Bound.-Lay. Meteorol., 37, 17-35, 1986.

Sayers, A. T.: Fluid mechanics, Oxford Univ Press, Cape Town, 483 pp., 1992.

Valentini, R., Matteucci, G., Dolman, A., Schulze, E., Rebmann, C., Moors, E., Granier, A., Gross, P., Jensen, N., Pilegaard, K., Lindroth, A., Grelle, A., Bernhofer, C., Grunwald, T., Aubinet, M., Ceulemans, R., Kowalski A., Vesala, T., Rannik, U., Berbigier, P., Loustau, D., Guomundsson, J., Thorgeirsson, H., Ibrom, A., Morgenstern, K., Clement, R., Moncrieff, J., Montagnani, L., Minerbi, S., and Jarvis, P.: Respiration As The Main Determinant Of Carbon Balance In European Forests, Nature, 404, 861-865, 2000.

Vickers, D. and Mahrt, L.: Quality control and flux sampling problems for tower and aircraft data, J. Atmos. Oceanic. Technol., 14, 512-526, 1997. 